Received: 15 January 2018

Accepted: 3 May 2018

Published online: 17 May 2018

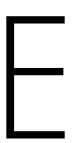

C N
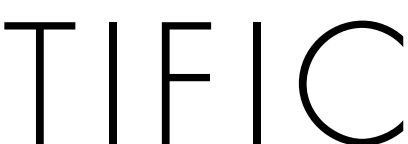

REP

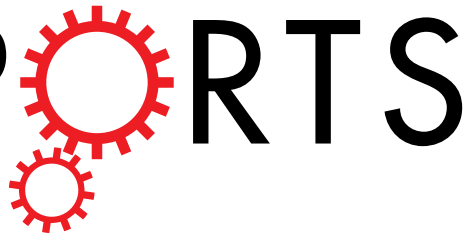

OPEN

\title{
Methanol fixed fibroblasts serve as feeder cells to maintain stem cells in the pluripotent state in vitro
}

Yahui Ren ${ }^{1}$, Ziyu Ma ${ }^{1}$, Tong Yu ${ }^{1}$, Min Ling ${ }^{2}$ \& Huayan Wang ${ }^{1}$

Preparation of mouse embryonic fibroblast (MEF) feeder cells to maintain pluripotent stem cells (PSCs) is time consuming and involved in animal issues. Here, we demonstrated a novel method to prepare feeder cells with high efficiency, timesaving, and low costs. MEFs in $3 \times 10^{4} \mathrm{cell} / \mathrm{cm}^{2}$ were fixed by methanol for $5 \mathrm{~min}$ and air drying for $5 \mathrm{~min}$. Thereafter, the methanol fixed MEF cells (MT-MEF) were able to be used directly to culture PSCs or stored at room temperature for the future usage. PSCs cultured on MT-MEF could be continuously expanded for over 40 passages with the naïve pluripotency. MT-MEFs could also be used to maintain human and pig iPSCs. Moreover, methanol fixed MEFs' culture dish was able to be reused for at least 4 times, and to be applied for antibiotic resistant screening assay to establishing stable transfected PSC lines. Alternatively, the immortalized cell lines, for instance NIH3T3 cells, could also be fixed by methanol and used as feeder cells to maintain PSCs. Thus, this novel means of methanol fixed feeder cells can completely replace the mitomycin $\mathrm{C}$ and gamma radiation treated MEF feeder cells, and be used to maintain PSCs derived from mouse as well as other animal species.

Pluripotent stem cells (PSCs), including embryonic stem cells (ESCs) and induced pluripotent stem cells (iPSCs), have a great promise in regenerative medicine, disease modeling, and cell therapies ${ }^{1-3}$. To culture PSCs, either mitomycin C (MMC) or gamma radiation treated mouse embryonic fibroblasts (MEFs) were commonly used as feeder cells to maintain the self-renewal and pluripotency ${ }^{4-6}$. Recently, expanded/extended potential stem cells (EPSCs) that contribute to both embryo proper and placenta trophoblasts in chimeras, were also established and cultured on MEF feeder cells ${ }^{7,8}$. The speculated reasons of using MMC-MEFs were due to that MEFs might produce and secrete growth factors, including leukemia inhibitory factor (LIF), fibroblast growth factor (FGF), and bone morphogenetic protein (BMP) etc. ${ }^{9-11}$, to maintain PSCs in the naïve pluripotent state. However, there were many inadequacies of using MMC and radiation treatment of MEF feeder cells. First, the preparation of MEFs is a complex and time consuming process ${ }^{12,13}$. Second, the MMC is pricey and residual MMC might produce cytotoxicologial effects on $\mathrm{ESCs}^{14}$. Additionally, application of gamma radiation requires the special equipment and devices ${ }^{15}$. Third, animal-derived MEFs retain the xenogeneic components that limit its application to culture human PSCs that may use to treat debilitating human diseases ${ }^{16,17}$. Therefore, feeder-free culture systems are the alternative approaches to replace MEF feeder cells. Culture dishes coated with the recombinant and synthesized macromolecules, including gelatin ${ }^{18}$, Matrigel $^{19}$, recombinant extracellular matrix proteins ${ }^{20-22}$, synthetic polymers $^{23,24}$, hydrogel ${ }^{25,26}$, recombinant E-cadherin substratum ${ }^{27}$, Glycosaminoglycan ${ }^{27}$, and Oligopeptide ${ }^{28}$, as well as 3D scaffold ${ }^{28-30}$, were developed and used to culture PSCs. However, these methods either use animal products that may have potential problems in transplantation applications or need special growth factors and media.

Recently, reports showed that chemicals glutaraldehyde (GA) and formaldehyde (FA) were able to fix feeder cells that were used to maintain the pluripotency of mouse and human PSCs ${ }^{31-33}$. The procedures of chemical fixation with GA and FA required to wash out GA and FA residues by PBS for multiple times, and then the fixed cells could be stored at $4{ }^{\circ} \mathrm{C}$ or freeze-dried first and stored at room temperature for further usage $\mathrm{e}^{31-33}$. The principle concept of GA and FA fixation of feeder cells may provide a convenient method to replace the traditional method to make feeder cells.

Extracellular matrix (ECM) influences adhesion, migration, differentiation and proliferation of stem cells through communicating with cell surface receptors and adhesion molecule such as integrins ${ }^{34-36}$. Methanol-fixed 
feeder cells, which are unable to produce growth factors and cytokines that PSCs required, still retain ECM proteins in the surface of fixed cells and provide niches and signaling for PSCs to control the balance between self-renewal and differentiation. Collagenase-IV is one of the matrix metalloprotinase, which degrades ECM proteins such as collagen-IV, fibronectin, laminin, and vitronectin ${ }^{37}$. Thus, the treatment of collagenase-IV is able to remove collagen-IV and fibronectin from the surface of methanol fixed feeder cells. Consequently, the pluripotency and adhesion ability of PSCs may be affected when cells are cultured on the collagenase-IV treated methanol fixed feeder cells.

In this study, we develop a novel method to maintain PSC self-renewal and pluripotency for the long-term expansion. Methanol-fixed feeder cells not only were used to culture mouse, human, and porcine pluripotent stem cells, but also were used for antibiotic-resistant screening and repeated usage. Meanwhile, we demonstrated that ECM proteins collagen-IV and fibronectin were crucial for PSCs attachment and maintaining naïve state pluripotency of PSCs.

\section{Results}

Culture of mouse ES on methanol-fixed feeder cells. The previous reports showed that cells fixed by glutaraldehyde (GA) and paraformaldehyde could be used as feeder cells to maintain mouse and human induced pluripotent stem cells ${ }^{31-33}$. To verify the chemical fixation method, we prepared feeder cells by GA following the procedure reported by Yue, X. S. ${ }^{32}$. The results showed that GA procedure was time consuming, and results were jagged. Alternatively, we used $100 \%$ methanol to fix cells, which is the first time reported, and found that methanol fixed MEF (MT-MEF) cells were able to maintain mouse PSCs. The J1 mES cells cultured on MT-MEF presented more domed and compact morphology compared to the control GA fixed MEF (GA-MEF) (Fig. 1A). Growth rate of J1 mES on MT-MEF was significantly increased versus on control GA-MEF (Fig. 1B). The expression level of Oct4, Nanog, and Sox2 was increased in J1 cells when cultured on MT-MEF (Fig. 1C). The ratio of SSEA-1 positive cell population could reach $97.5 \%$ on MT-MEF versus $89.5 \%$ on GA-MEF feeders (Fig. 1D). Additionally, the scanning electron microscope analysis of MT-MEF, GA-MEF, and MMC-MEF showed that the cellular membrane of MT and GA fixed cells presented the smooth surface, but the MMC treated cell membrane displayed the net-like structure, indicating that chemical components indeed changed the cellular membrane structure of fixed cells (Fig. 1E), in which the cytoplasmic proteins may be released to the surface of cell membrane and play a role for PSC adhesion.

Besides MEF, we also used epithelial cell PK-15, myoblast $\mathrm{C} 2 \mathrm{C} 12$, and porcine embryonic fibroblast (PEF) fixed by methanol to culture J1 mES. Results showed that J1 mES could be maintained naïve morphology and alkaline phosphatase (AP) activity on MT fixed cells no matter cell types and where cells coming from (Fig. 1F). As control experiments, we did the parallel assays by culturing J1 cells on plates coated with gelatin, Matrigel, laminin, and poly-L-Lysine (Fig. S1). Results indicated that methanol fixation method is easier to handle, low cost, and shows the better result of maintenance of PSC pluripotency.

Optimizing the methanol-fixed method. Because of the application of methanol and acetone in histochemistry and cytochemistry, we initially mixed methanol and acetone in the ratio of 5:5 and used to fix MEF cells. The J1 cells could be maintained on methanol and acetone (5:5) fixed MEF cells for long term passages with the domed morphology and AP positive staining (Fig. S2A). We then used the different proportion of methanol and acetone to fix MEF cells and detected the effect on the culture of pluripotent stem cells. Results of cell morphology and AP staining showed that when MEF cells were fixed by methanol and acetone at ration of 3:7, the AP staining of J1 cells was faded (Fig. S2A), the Oct4 and Nanog expressions were decreased (Fig. S2B), and the number of AP positive colonies was reduced (Fig. S2C). Alternatively, when use of methanol only to fix MEF cells, J1 cells were maintained excellently (Fig. S2A). Based on this observation, acetone was removed from formula and methanol solely was used to fix feeder cells. To test the efficacy of methanol concentration, MEF and NIH3T3 cells were treated with different concentration of methanol from $10 \%$ to $100 \%$. Feeder cells treated with low concentration of methanol were unable to adhere on culture dish firmly and most of feeder cells were floated when medium was added back to the dish (Fig. S3). Based on this experiment, 100\% methanol was used to fix feeder cells. Meanwhile, the control experiment of incubation of $\mathrm{H}_{2} \mathrm{O}$ with feeder cells was performed. The $\mathrm{H}_{2} \mathrm{O}$ treated cells were unable to be used as feeder cells, showing the similar results as seen in 10\% methanol treatment (Fig. S4). The layout of methanol fixation and its applications is presented in Fig. $2 \mathrm{~A}$.

Next, we optimized the conditions of methanol-fixed method. The methanol stored at room temperature (RT), $4^{\circ} \mathrm{C}$, and $-20^{\circ} \mathrm{C}$, respectively, was used to fix feeder cells, which were then used for culturing J1 cells. There was no influence on J1 mES morphology and AP staining when feeder cells were fixed by methanol in different temperatures (Fig. 2B). Therefore, we selected $4^{\circ} \mathrm{C}$ methanol to fix cells. Then, we cultured J1 cells on MT-MEF cells that were fixed for 5 to $20 \mathrm{~min}$ at room temperature and found that $5 \mathrm{~min}$ treatment was adequate for the fixation of MEFs (Fig. 2C). To optimize the concentration of feeder cells, MEFs from $0.5 \times 10^{4} / \mathrm{cm}^{2}$ to $3 \times 10^{4} / \mathrm{cm}^{2}$ were fixed by methanol and used to culture J1 cells. Results of cell morphology and AP staining confirmed that the concentration of feeder cells should be over $1.5 \times 10^{4} / \mathrm{cm}^{2}$ (Fig. 2D). Too less of feeder cells could influence the pluripotency of stem cells.

To test the storage term of MT-MEF cells, the fixed MEFs were stored at $4{ }^{\circ} \mathrm{C}$ (Fig. S5A,B), $37^{\circ} \mathrm{C}$ (Fig. S5C,D), and room temperature (Fig. 2E,F) for up to 21 days. The cell morphology and expression level of pluripotent genes indicated that plates coated with MT-MEF cells could be stored for a long term no matter the variation of storage temperatures as long as the fixed cells were dehydrated. Based on above investigations, the optimized condition for methanol fixation is: methanol at $4{ }^{\circ} \mathrm{C}$, fixation of cells for $5 \mathrm{~min}$ at RT, and the density of $3 \times 10^{4} / \mathrm{cm}^{2}$ cells on a plate. Finally, the fixed MEF plate can be stored at RT for at least three weeks. 
A
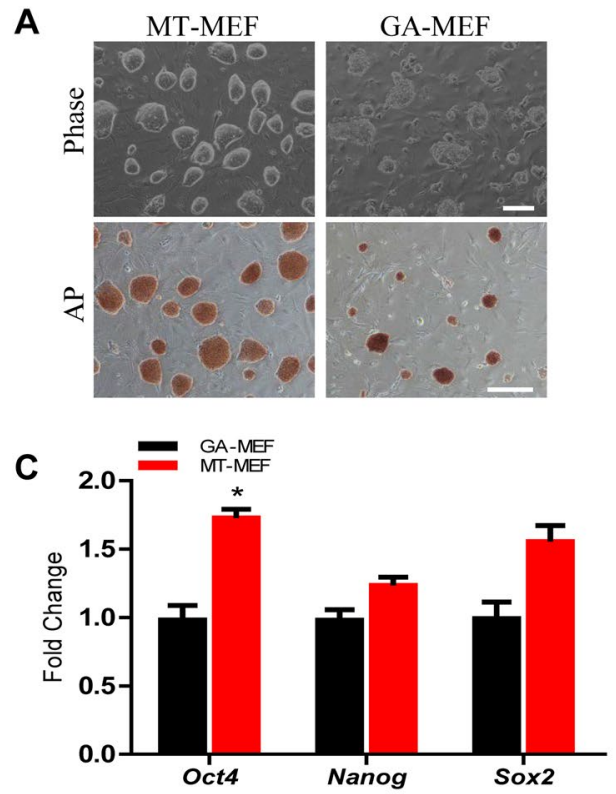

E
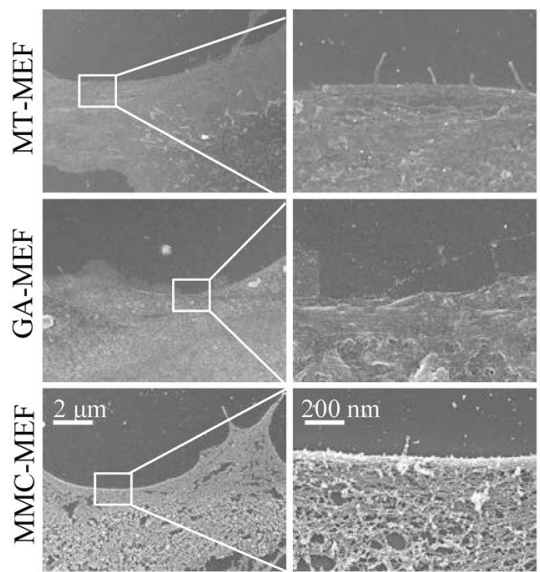

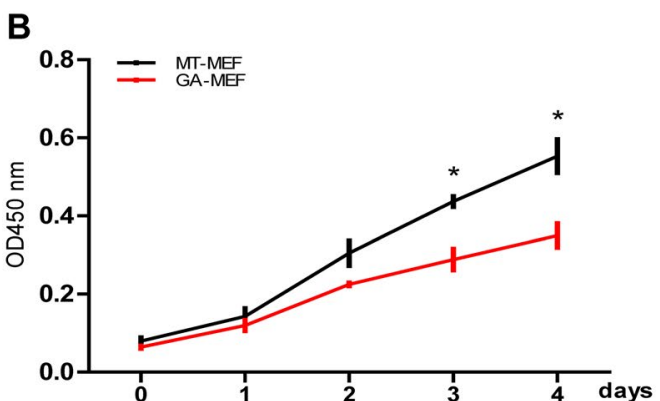

D
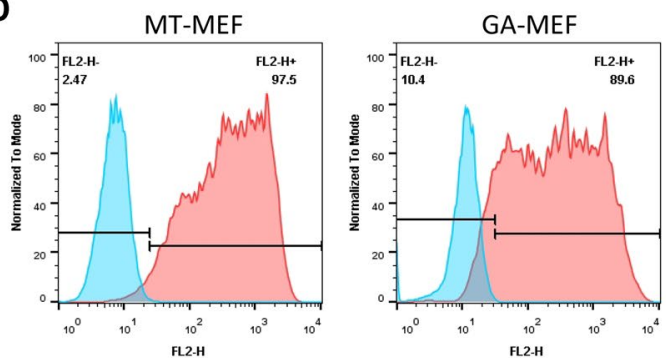

$\mathbf{F}$

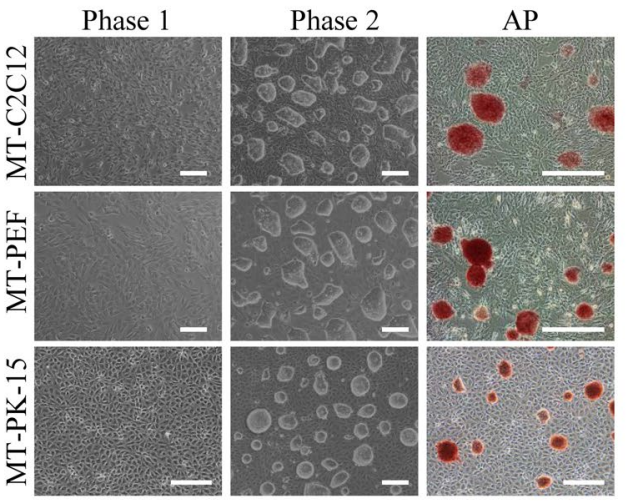

Figure 1. Culture of mouse ES on fibroblasts fixed by methanol. J1 mES cells were cultured on MEF cells fixed by MT (MT-MEF) and GA (GA-MEF), respectively. (A) Morphology and AP staining of J1 mES cells. (B) Growth curve of J1 cells. (C) qRT-PCR analysis of Oct4, Nanog, and Sox2 expressions in J1 cells. (D) Flow cytometry analysis of SSEA-1 expression in J1 cells. (E) Scanning electron microscope analysis of MT-MEF, GAMEF, and MMC-MEF. (F) J1 cells were cultured on MT fixed C2C12, PEF, and PK-15 cells. Phase 1, MT fixed cells; Phase 2, morphology of J1 cells cultured on MT fixed cells. Scale bar, $200 \mu \mathrm{m}$. Data indicate mean \pm SD, $* \mathrm{P}<0.05, \mathrm{n}=3$.

Maintenance of self-renewal and pluripotency of mouse PSCs on methanol fixed fibroblasts. Mouse ES J1 and iPS cells were seeded on methanol fixed MEF (MT-MEF) cells, NIH3T3 (MT-3T3) cells, and mitomycin C treated MEF (MMC-MEF) cells, respectively. The morphology and AP activity of J1 and miPS cells cultured on MT-MEF and MT-3T3 were similar to that cultured on MMC-MEF, presenting the compact and domed cell types (Figs 3A, S6A). There was no difference of growth rate of J1 cells on MT-MEF and MT-3T3 versus on MMC-MEF (Fig. 3B). We did qRT-PCR analysis of pluripotent genes using J1 cells that were continuing cultured on MT-MEF for 25 passages and on MT-3T3 for 20 passages, and miPS cells that were continuing cultured on MT-MEF for 20 passages and on MT-3T3 for 18 passages. Results indicated that expression of Oct4 and Nanog from cells on MT-MEF and MT-3T3 was increased versus on MMC-MEF, and Sox2 expression was significantly upregulated (Figs 3C, S6B). Protein expressions of OCT4 and SSEA-1 in J1 cells, which were continuing cultured on MT-MEF for 30 passages and on MT-3T3 for 25 passages, and miPS cells that were continuing cultured on MT-MEF for 25 passages and on MT-3T3 for 23 passages, were confirmed by immunofluorescence assays (Figs 3D, S6C) and the flow cytometry analysis (Figs 3E, S6D). To further identify the pluripotency of stem cells cultured on MT-MEF and MT-3T3, J1 cells, which were continuing cultured on MT-MEF for 24 passages and on MT-3T3 for 19 passages, and miPS cells, which were continuing cultured on MT-MEF for 15 passages and on MT-3T3 for 13 passages, were carried out the teratoma formation assay. As expected, J1 and miPS cells on MT-MEF and MT-3T3 were able to differentiate into all three germ layers in vivo (Figs 3F, S6E). 
A

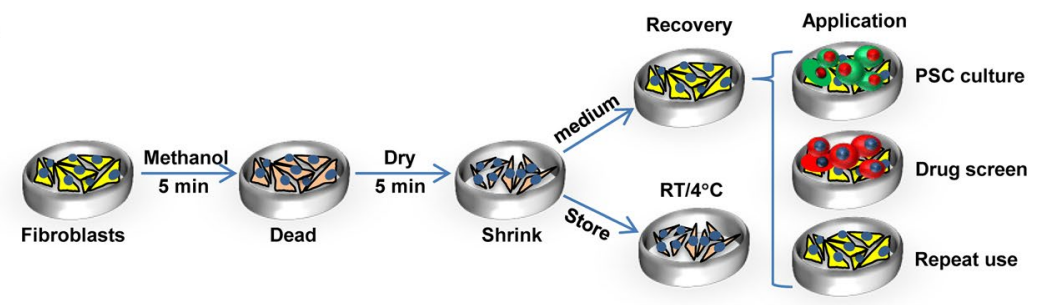

B

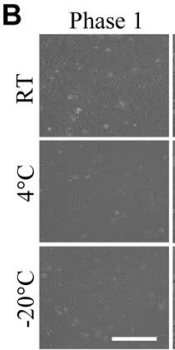

C

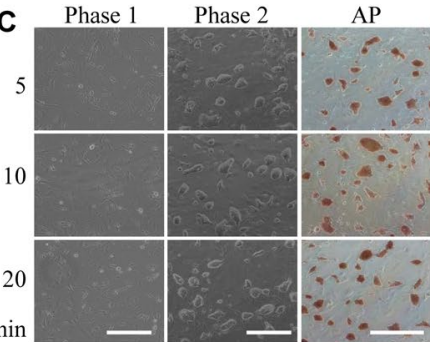

D

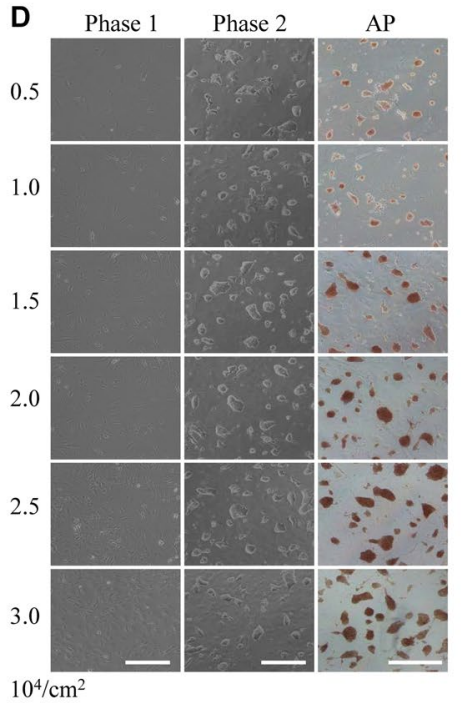

$\mathrm{E}$

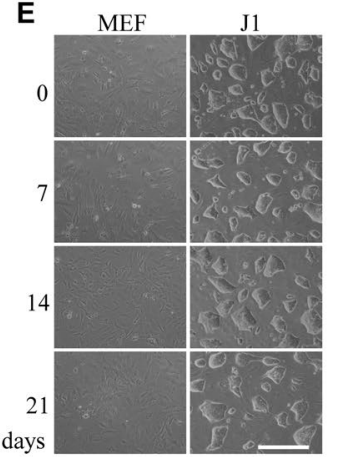

$\mathbf{F}$

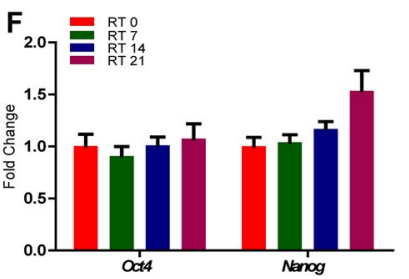

Figure 2. Optimizing procedure of methanol fixation. The J1 mES cells were cultured on methanol fixed MEF cells (MT-MEF) under different conditions. (A) Schematic diagram of procedure and application of MT-MEF. (B) Methanol in different temperatures was used to fix MEFs. (C) MEFs were fixed by methanol for 5 to $20 \mathrm{~min}$. (D) MEFs in the density from $5 \times 10^{3} / \mathrm{cm}^{2}$ to $3 \times 10^{4} / \mathrm{cm}^{2}$ were fixed by methanol. (E) MT-MEFs stored at room temperature (RT) for 0 to 21 days. (F) qRT-PCR analysis of Oct4 and Nanog expressions in J1 cells cultured on MT-MEF that was stored at RT for different dates (0 to 21 days). Phase 1, morphology of MT-MEF; Phase 2, morphology of J1 cells cultured on MT-MEF. Scale bar, $400 \mu \mathrm{m}$ for B-D, $200 \mu \mathrm{m}$ for E.

These results indicated that both mES and miPS cells could maintain their self-renewal and pluripotency on methanol fixed fibroblasts for long term passages.

Growth of human and porcine iPS cells on methanol fixed fibroblasts. Commonly, human induced pluripotent stem (hiPS) cells are maintained either on MMC-MEF feeder cells with KSR medium (Fig. 4Ad) or on Matrigel with mTeSR medium (Fig. 4Af) ${ }^{38,39}$. To test whether methanol fixed fibroblasts can be used for culturing human pluripotent stem cells, we cultured hiPS on MT-MEF (Fig. 4Aa), MT-3T3 (Fig. 4Ab), and MT-hMSC (Fig. 4Ac) in KSR medium, and on MT-MEF (Fig. 4Ae) in mTeSR medium for 8 passages. The hiPS morphology did not present any visible changes when cells were cultured on methanol fixed fibroblasts versus on MMC treated MEFs. The pluripotent gene expressions of OCT4 and SOX2 detected by immunofluorescence assay (Fig. 4B) and hiPS specific surface marker SSEA-4 detected by flow cytometry (Fig. 4C) further confirmed that methanol fixed fibroblasts could be used to maintain the pluripotency of hiPS cells.

We also used methanol fixed fibroblasts to maintain porcine induced pluripotent stem (piPS) cells and confirmed that piPS cells cultured on MT-MEF and MT-3T3 retained the typical morphology and positive alkaline phosphatase activity (Fig. 4D). The expression level of pluripotent genes OCT4, SOX2, NANOG, and ESRRB of piPS was no change comparing to that on MMC-MEF (Fig. 4E). These observations indicate that methanol fixed fibroblasts can be used not only to maintain mouse PSCs, but also to maintain pluripotent stem cells from other animal species.

Application of methanol fixed fibroblasts for drug screening and repeated usage. The mitomycin $\mathrm{C}$ treated feeder cells are unable to be used to perform the drug-screen related experiments since the living MEF feeders have the limited tolerance on the high concentration of antibiotic treatment. However, methanol fixed fibroblasts could be used for screening the stable antibiotic-resistant stem cell lines within 14 days (Fig. 5A). We have established several puromycin-resistant stem cell lines that were based on methanol fixed MEF and NIH3T3 cells and through the stable transfection. The puromycin-resistant cell lines include J1 mES cells with miR370 transfection (J1/miR370), and porcine iPS cells with METTL3 transfection (piPS/METTL3) and with 
A

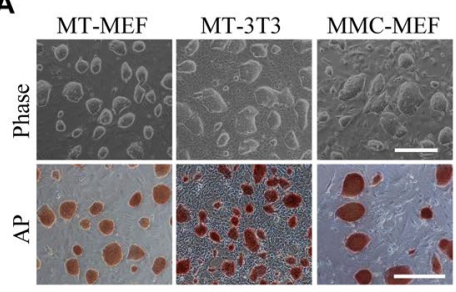

D

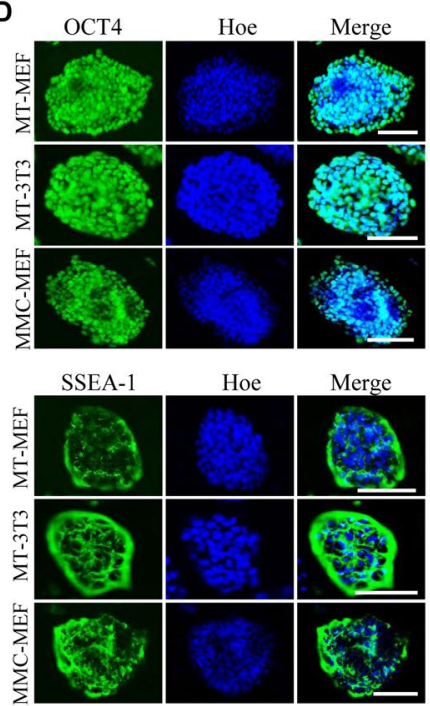

B

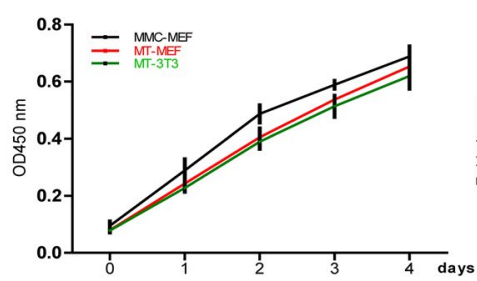

C

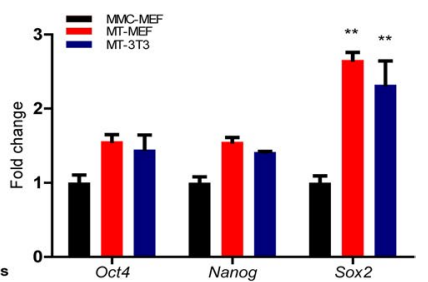

E
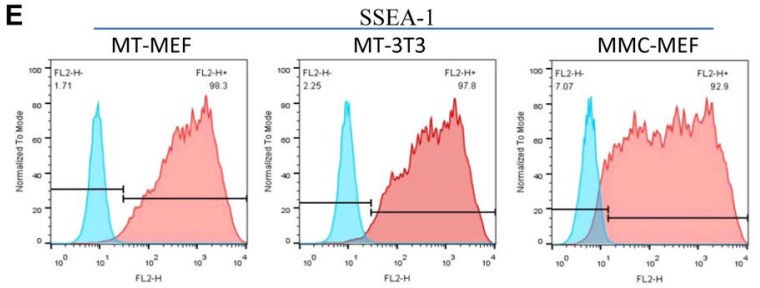

$\mathbf{F}$

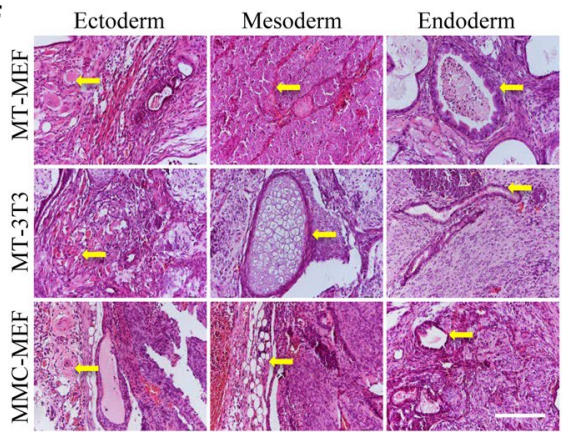

Figure 3. Maintenance of self-renewal and pluripotency of J1 mES on methanol fixed fibroblasts. J1 mES cells were cultured on methanol fixed MEF (MT-MEF) and NIH3T3 (MT-3T3) cells, and Mitomycin C treated MEF (MMC-MEF). (A) Morphology and AP staining of J1 mES cells. (B) Growth curve of J1 mES. (C) qRT-PCR analysis of pluripotent genes in J1 mES. (D,E) Immunofluorescence (D) and flow cytometry analysis (E) of pluripotent markers OCT4 and SSEA-1 in J1 mES. Nuclei were stained by Hoechst 33342 (Hoe). (F) Teratoma formation of $\mathrm{J} 1 \mathrm{mES}$. Arrows indicate tissues from the three germ layers. Scale bar, $400 \mu \mathrm{m}$ for A, $200 \mu \mathrm{m}$ for F, and $100 \mu \mathrm{m}$ for $\mathrm{D}$.

miR370 (piPS/miRNA370) (Fig. 5B). Accordingly, the stable antibiotic-resistant pluripotent stem cells can be screened and continuing cultured on methanol fixed fibroblasts.

Since methanol fixed fibroblasts can resist $0.25 \%$ Trypsin-EDTA digestion, we asked whether methanol fixed fibroblasts could be repeatedly used to culture pluripotent stem cells. The J1 cells were cultured on the plate coated with MT-MEF (Fig. 5C) and MT-3T3 (Fig. 5D) for 3 days, and then J1 cells were digested by $0.25 \%$ Trypsin-EDTA and removed from the plate (R0). The R0-plate washed briefly by PBS was reused for culturing J1 cells again. The plate coated with methanol fixed fibroblasts could be repeatedly used up to 4 times (R1-R3). The flow cytometry analysis showed that SSEA-1 positive J1 cells in R0-plate were 98.5\% on MT-MEF (Fig. 5E) and $97.1 \%$ on MT-3T3 (Fig. 5F), but SSEA-1 positive J1 cells in R3-plate were dropped to 90.3\% on MT-MEF and $91.2 \%$ on MT-3T3, indicating that even reused for four times there still were 90 percent J1 cells grown on methanol fixed fibroblasts coated plate. In general, the methanol fixed fibroblasts can be reuse for several times to save time and lower preparation cost.

Treatment of proteolytic enzymes on methanol fixed fibroblasts. Extracellular matrix (ECM) proteins play major roles on attachment, migration, and signal transduction, and are the key factors to maintain self-renewal and pluripotency of stem cells ${ }^{34-36}$. Though methanol fixed fibroblasts are already dead, pluripotent stem cells can attach tightly and maintain pluripotency state well. We hypothesized that ECM proteins were still existed in the surface of methanol fixed fibroblasts. Immunofluorescence assay confirmed that ECM proteins fibronectin and collagen-IV were in MEF (Fig. 6A) and NIH3T3 (Fig. S7A) cells treated with methanol.

Collagenase-IV is a metalloprotease that degrades ECM proteins such as collagen-IV and fibronectin ${ }^{37}$. We identified that collagen-IV and fibronectin were degraded from MT-MEF (Fig. 6B) and MT-3T3 (Fig. S7B) cells, which were treated by collagenase-IV for $20 \mathrm{~min}$. As long as 5-min collagenase-IV treatment on MT feeder cells, J1 cells were unable to grow well and many colonies were suspended (Figs 6C, S7C). The number of adherent colonies was reduced significantly on MT-MEF (Fig. 6D) and MT-3T3 (Fig. S7D) feeders that were treated by collagenase-IV for $20 \mathrm{~min}$. The gene expression of J1 cells cultured on MT-MEF treated by collagenase-IV for $20 \mathrm{~min}$ showed that naïve state genes Rex 1 and $\mathrm{Klf} 2$ were reduced and primed state genes Otx 2 and Fgf5 were increased comparing with J1 cultured on MT-MEF (Fig. 6E). These results demonstrated that ECM proteins collagen-IV and fibronectin were crucial for adhesion and naïve state maintenance of PSCs (Fig. 6F). 
A
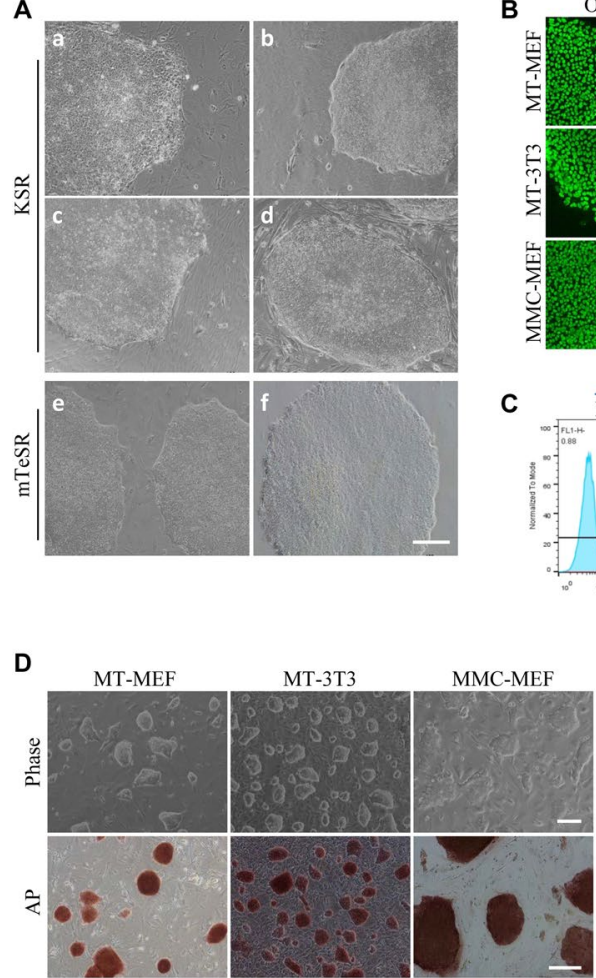
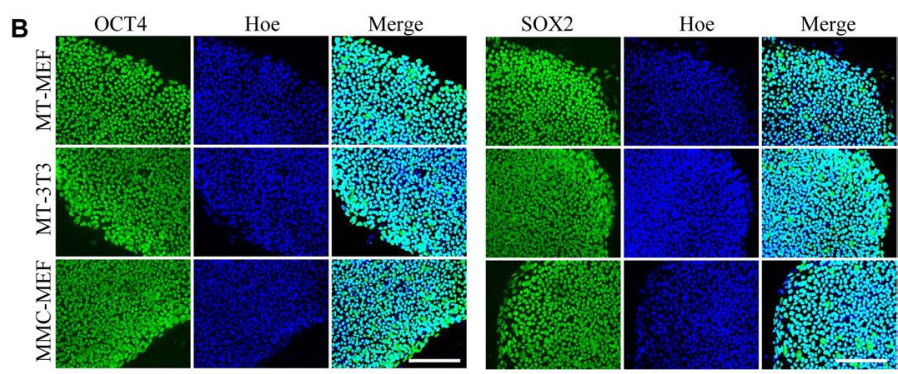

C

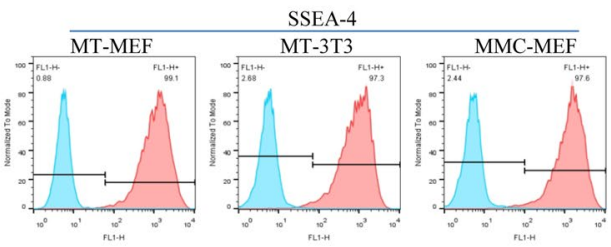

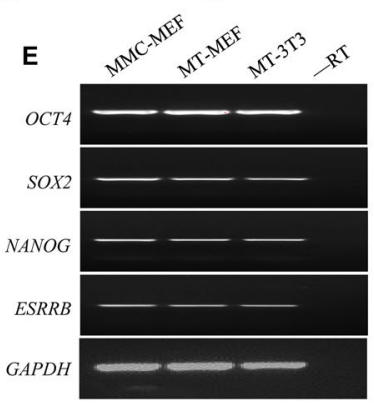

Figure 4. Human and porcine iPS cells were maintained on feeders derived from methanol fixed fibroblasts. (A) Human iPS cells were cultured on MT-MEF (a), MT-3T3 (b), MT-hMSC (c), and MMC-MEF (d) in KSR medium, and on MT-MEF (e) and Matrigel (f) in mTeSR medium. (B) Immunofluorescence analysis of OCT4 and SOX2 expressions in human iPS cells. (C) Flow cytometry analysis of SSEA-4 in human iPS cells. (D) Porcine iPS cells were cultured on MT-MEF, MT-3T3, and MMC-MEF. (E) RT-PCR analysis of OCT4, SOX2, NANOG, and ESRRB expressions in porcine iPS cells. Scale bar, $200 \mu \mathrm{m}$.

\section{Discussion}

Normally, ES and iPS cells were cultured on mitomycin C or gamma radiation treated MEF feeder cells ${ }^{4-6}$. Preparation of MEF feeder cells needs the primary embryonic fibroblasts that are isolated from E12.5 mouse embryo and expanded in vitro for one to three passages ${ }^{12,13}$. Therefore, making MEF feeder cells is time consuming and involved in multiple processes that may lead to the cross contaminations. Using chemical fixer GA and FA to fix feeder cells provides an alternative approach to produce MEF feeders and maintain pluripotency of PSCs ${ }^{31-33}$. The low concentration of FA/GA was able to sustain the membrane fluidity that was correlated to the biological activity to maintain $\mathrm{PSCs}^{40}$. In this study, we found that methanol could also be as the chemical fixer to straightforwardly make MT-MEF feeder cells, which is very maneuverable and reproducible, and also the plate with methanol fixed feeder cells is able to be stored at room temperature for a long term and to be reused for multiple times. We also demonstrated that ECM proteins in the surface of methanol fixed cells were important for the adhesion of stem cells.

There are several great advantages of methanol fixed feeder cells versus the traditional mitomycin $\mathrm{C}$ treated MEF feeder cells. First, since methanol fixed fibroblasts can be stored at room temperature for a long term (up to 21 days), plates with methanol fixed feeder cells can be made in large scale once and for all, saving time and reducing costs. Second, unlike mitomycin $\mathrm{C}$ treated MEFs, methanol fixed cells can theoretically provide a germ-free feeder and significantly reduce the cross contaminations because all proteins inside and outside of cells have been fixed by methanol. Third, unless MEFs were previously transfected by drug-resistant gene, mitomycin $\mathrm{C}$ treated MEFs cannot be used to perform drug-resistant screening assays, instead, methanol fixed fibroblasts could be directly used for drug screening experiments. Furthermore, we found that besides MEFs the commercial cell lines, including fibroblast NIH-3T3, myoblast C2C12, and porcine kidney epithelium PK-15 cells, could be fixed by methanol and used as feeder cells. The PSCs cultured on MT-3T3 feeders were maintained the pluripotency similar to that on MT-MEF and MMC-MEF. This discovery extremely extends the applications of methanol fixation method and has the potential for the commercial products.

In addition to the traditional MEF feeder cells, more and more feeder-free culturing systems for PSCs were developed, which include Matrigel ${ }^{19}$, laminin $^{21}$, recombinant fibronectin ${ }^{20}$, vitronectin $^{22}$, and 3D-hydrogel ${ }^{25,26}$ were specially used to culture human PSCs, providing a xeno-free condition for the expansion and clinical application of hPSCs. However, the culture dish coated by artificial matrixes is pricey and needs particular media and growth factors. Therefore, feeder-free culturing systems are limited for the large-scale preparation of PSCs. Alternatively, the methanol fixation method is simple and economical, which can be easily used for large scale preparation of PSCs. 
A
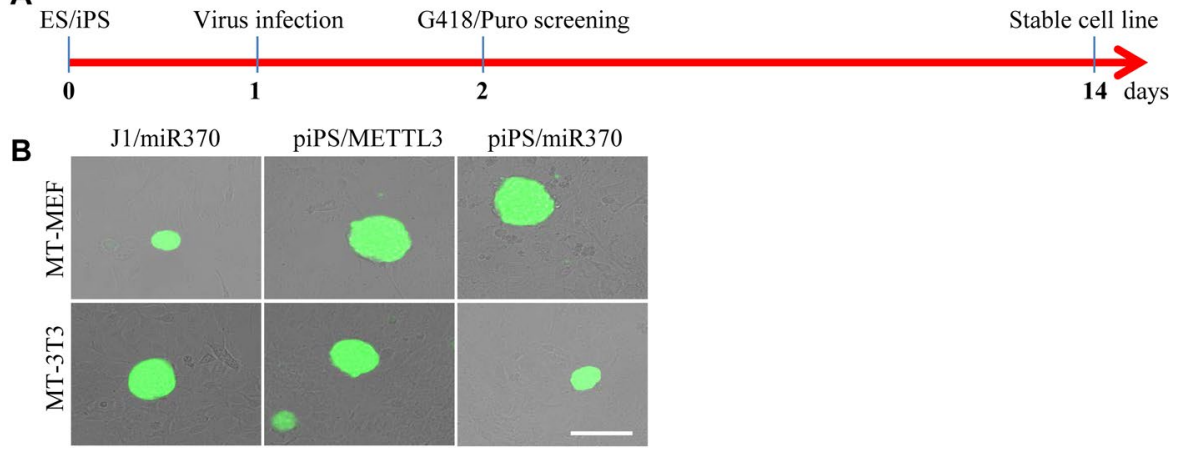

C

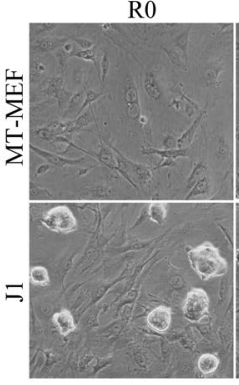

R1

R2

R3

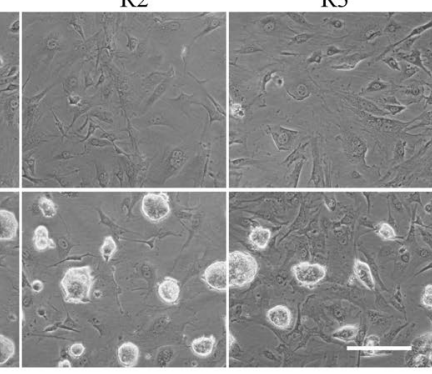

D

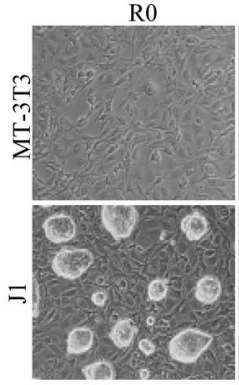

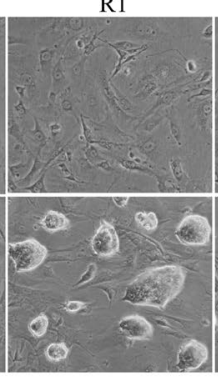

R1

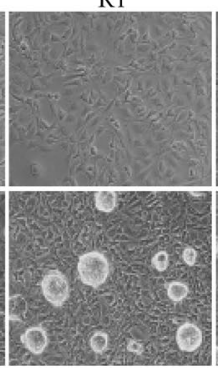

R2

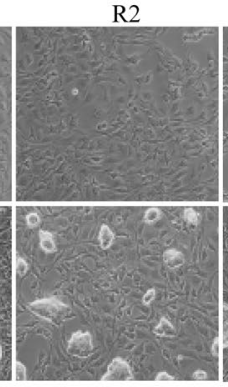

R3

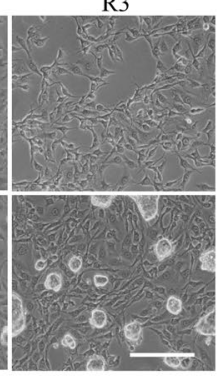

E.

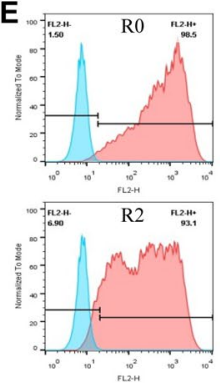

F

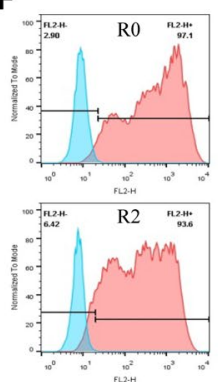

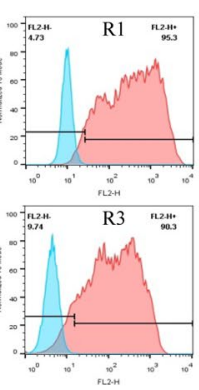

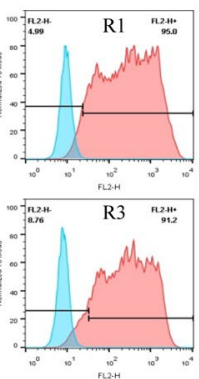

Figure 5. Application of methanol fixed fibroblasts for drug screening and repeated usage. (A) Diagram of drug screening. (B) The stably transfected cell lines derived from J1 cells transfected by miR70/EGFP and piPS cells transfected by METTL3-EGFP and miR370/EGFP, respectively, which were cultured on MT-MEF and MT-3T3. (C,D) Repeated usage of MT-MEF (C) and MT-3T3 (D) for four times (R0-R3). (E,F) Flow cytometry analysis of SSEA-1 expression in J1 mES cultured on MT-MEF (E) and MT-3T3 (F), which were used repeatedly for four times (R0-R3). Scale bar, $100 \mu \mathrm{m}$ for B, $200 \mu \mathrm{m}$ for C and D.

The reasons why pluripotent stem cells should be cultured on feeder cells to maintain their undifferentiated state were not clear so far. Previously, we and others thought that mitomycin C and radiation treated MEF feeder cells were able to produce and secret growth factors and cytokines to provide an environment to maintain pluripotency of PSC ${ }^{9-11}$. However, in this study, we found that MEF feeder cells were died after be fixed by methanol and couldn't produce growth factors and cytokines supporting PSC growth. Consequently, growth factors and cytokines that secret from MEF feeder cells are not necessary for maintaining PSCs. On the other hand, extracellular matrix proteins in the surface of feeder cells were reported to play important role in cell attachment and maintaining pluripotency of PSCs ${ }^{34-36}$. We detected extracellular matrix proteins collagen-IV and fibronectin in methanol fixed fibroblasts and confirmed that they exist in fibroblasts even after be treated by methanol. Besides, the significance of topology ${ }^{41-43}$ and traction ${ }^{44-46}$ between pluripotent stem cells and their adhesion surface was reported in recent years. Our experiments demonstrated that ECM proteins were crucial in adhesion and pluripotency to maintain PSC. In this study, we only detected two ECM proteins collagen-IV and fibronectin, whether other ECM proteins also played role in adhesion for PSCs were not known yet. We hypothesis that the role of feeder cells for PSC is the joint action including ECM proteins, cell adhesion molecules, topology, traction and others that may not be investigated yet.

\section{Conclusions}

In summary, our novel method can substitute traditional method for making feeder cells completely. In addition to MEF cells, commercial cell lines including immortalized fibroblasts, myoblasts, and epithelium cells can be fixed by methanol and used to culture pluripotent stem cells. Not only mouse PSCs, but also PSCs from other species can be cultured on methanol fixed fibroblasts. Methanol fixed fibroblasts can be reused and used for screening antibiotic selection to establish stable pluripotent stem cell lines. We also demonstrate that ECM proteins collagen-IV and fibronectin play a crucial role for adhesion and maintaining pluripotency of PSCs. 
A

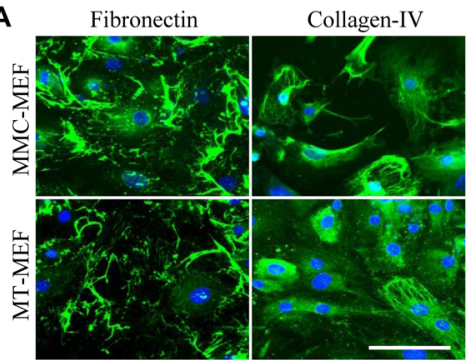

C

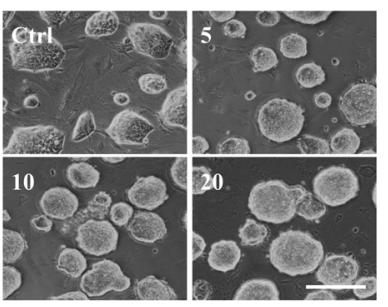

E

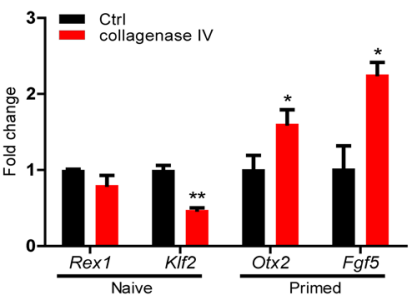

B

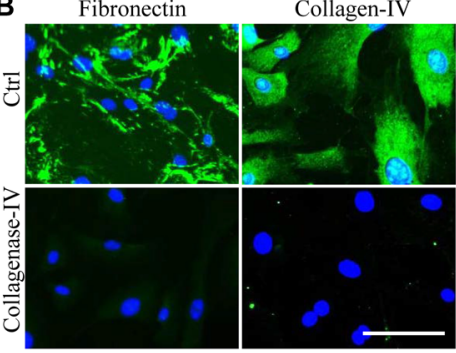

D

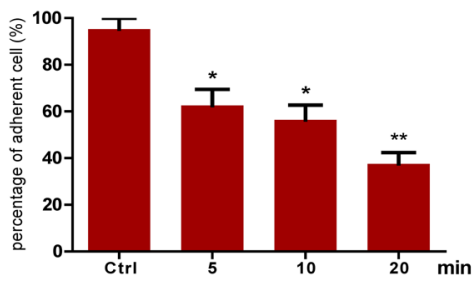

$\mathbf{F}$

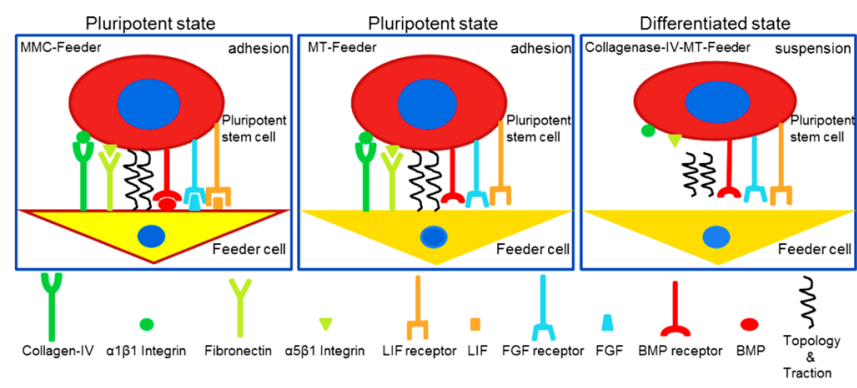

Figure 6. The treatment of proteolytic enzymes on MT-MEF. (A) Immunofluorescence analysis of fibronectin and collagen-IV expressions in MT-MEF and MMC-MEF. (B) Immunofluorescence analysis of fibronectin and collagen-IV expressions in MT-MEF (Ctrl) and MT-MEF treated by collagenase-IV. (C) J1 cells cultured on MT-MEF were treated by collagenase-IV for 5, 10, and $20 \mathrm{~min}$. (D) Percentage of J1 cell adherent on MT-MEF treated by collagenase-IV for different times. (E) qRT-PCR analysis of expression of naïve and primed markers in J1 cells cultured on MT-MEF (Ctrl) and MT-MEF treated by collagenase-IV. (F) Diagram of interaction between different feeder cell niches and pluripotent stem cells. Ctrl, MT-MEF without treatment. Scale bar, $100 \mu \mathrm{m}$ for $\mathrm{A}$ and $\mathrm{B}, 200 \mu \mathrm{m}$ for C. Data indicate mean $\pm \mathrm{SD}, * \mathrm{P}<0.05, * * \mathrm{P}<0.01, \mathrm{n}=3$.

\section{Methods}

Animals. The usage of live ICR mice for making mouse embryonic fibroblasts (MEFs) in this study was approved by Animal Care and Use Committee, which was subjected to Experiment Manage Committee of Northwest A\&F University. The experimental protocols that are involved in animal samples were based on the guideline approved by the Animal Research Committee of Northwest A\&F University. The nude mice used for teratoma experiments and tissue sections were conducted and paid in the Experimental Animal Center of Fourth Military Medical University, which has the licensed animal research facility and provides the commercial services. All methods were carried out in accordance with relevant guidelines and regulations.

Preparation of feeder cells. To prepare feeders, MEF cells were cultured on culture dish with MEF medium (DMEM high glucose plus 15\% FBS) to $80-90 \%$ confluence and then $10 \mu \mathrm{g} / \mathrm{mL}$ mitomycin C was added. After $2.5 \mathrm{~h}$ incubation at $37^{\circ} \mathrm{C}$, mitomycin $\mathrm{C}$ was removed and cells were washed with phosphate buffer saline (PBS) for 3 times. Cells were digested with $0.25 \%$ Trypsin-EDTA and then be used immediately or stored in liquid nitrogen. To prepare glutaraldehyde (GA) fixed MEF feeder, cells were cultured in culture dish with MEF medium to $80-90 \%$ confluence and then fixed with $2.5 \%$ glutaraldehyde as reported previously ${ }^{31-33}$. To prepare methanol fixed feeders, MEFs were cultured with MEF medium and NIH3T3 cells were cultured with NIH3T3 medium (DMEM high glucose plus $10 \%$ FBS). When cells were in $80-90 \%$ confluence, media were removed and cells were washed with PBS once. The $100 \%$ methanol precooled at $4{ }^{\circ} \mathrm{C}$ was added into the dish for $5 \mathrm{~min}$ at room temperature. After removing methanol, the dish was opened and placed on the surface of flow hood clean bench for $5 \mathrm{~min}$ to make sure that methanol was fully volatilized, and the fixed cells were dehydrated. Cells treated by methanol are ready to be used as feeders immediately or be stored at room temperature for future use. As the control experiment, cells were treated by $\mathrm{H}_{2} \mathrm{O}$ for $5 \mathrm{~min}$ at room temperature, and then following the similar steps of methanol treatment. 
Expansion of mES and miPS on methanol-fixed fibroblasts. J1 mES cells were purchased from ATCC and miPS cells were induced by our lab colleagues. J1 mES and miPS cells were digested into single cells with $0.25 \%$ Trypsin-EDTA and then seeded on methanol-fixed MEF and NIH3T3 feeders in normal mES medium including DMEM high glucose supplemented with 15\% FBS, $0.1 \mathrm{mM}$ non-essential amino acids (NEAA, Gibco, USA), $1 \mathrm{mM}$ L-glutamine (Gibco, USA), $0.1 \mathrm{mM} \beta$-mercaptoethanol ( $\beta$-met, Sigma, USA) and $10^{3}$ units $/ \mathrm{mL}$ mLIF (ESG1107, Millipore). Media were changed every two days.

Human and porcine iPS cultured on methanol-fixed MEF and NIH3T3 cells. Human iPS cells were purchased from SiDan Sai Biotechnology Co., Ltd. and porcine iPS cells were induced by our lab colleagues with Tet-On system. The hiPSCs were seeded on methanol-fixed MEF and NIH3T3 feeder cells, and cultured with DMEM/F12 supplemented with 20\% KSR (Gibco, USA), $0.1 \mathrm{mM} \mathrm{NEAA,} 1 \mathrm{mM}$ L-glutamine, $0.1 \mathrm{mM} \beta$-met and $10 \mathrm{ng} / \mathrm{mL}$ bFGF (100-18B, PeproTech) or with $\mathrm{mTeSR}^{\mathrm{TM}} 1$ medium (\#85850, STEMCELL Technologies). The piPSCs were seeded on methanol-fixed MEF and NIH3T3 feeder cells with DMEM supplemented with $15 \%$ FBS, $0.1 \mathrm{mM}$ NEAA, $1 \mathrm{mM}$ L-glutamine, $0.1 \mathrm{mM} \beta$-met, $10 \mathrm{ng} / \mathrm{mL}$ hLIF (LIF1050, Millipore) and $10 \mathrm{ng} / \mathrm{mL} \mathrm{bFGF}$ (100-18B, PeproTech). Media were changed every two days.

RT-PCR. Total RNAs were extracted by Trizol Reagent (Thermo Fisher Scientific, USA) according to the manufacturer's procedure. RNAs were examined by measuring OD260/280 ratio, and samples with a ratio of 2.0 were used for reverse transcription. One microgram total RNAs were reverse-transcribed with oligo-dT primer (Thermo Fisher Scientific, USA) using RevertAid ${ }^{\mathrm{TM}}$ reverse transcriptase (Thermo Fisher Scientific, USA). RT-PCRs were performed using $2 \times$ Es Taq MasterMix (CW Biotech, China) for 30 cycles at $94^{\circ} \mathrm{C} 30 \mathrm{~s}, 58^{\circ} \mathrm{C}$ $30 \mathrm{~s}$, and $72^{\circ} \mathrm{C} 30 \mathrm{~s}$. Non-RT negative controls (RT-) were also performed to monitor non-specific reactions, and Gapdh was used as internal controls. Quantitative RT-PCRs (qRT-PCR) were performed using a 10-fold dilution of cDNA with SYBR Green PCR Master Mix (TRANSGEN BIOTECH, China), and detected with StepOnePlus Real-Time PCR System (Applied Biosystems, USA). Measurements were performed on three biological replicates and each reaction was performed in triplicate. The expression level of target gene was normalized to the expression level of Gapdh. Melting curve analysis was conducted to confirm the specificity. Primers used in this study are listed in Supplementary Table S1.

Alkaline phosphatase staining. The alkaline phosphatase (AP) activity of pluripotent stem cells was determined by AST Fast Red TR and $\alpha$-Naphthol AS-MX Phosphate (Sigma Aldrich, USA) according to the manufacturer's instructions. Briefly, cells were washed twice using ice-cold PBS, fixed with $4 \%$ paraformaldehyde in PBS ( $\mathrm{pH}$ 7.4) for $15 \mathrm{~min}$ at room temperature, followed by washing three times using ice-cold PBS. Cells were then incubated at room temperature in the solution containing $1.0 \mathrm{mg} / \mathrm{mL}$ Fast Red TR, $0.4 \mathrm{mg} / \mathrm{mL} \alpha-\mathrm{Naphthol}$ AS-MX in $0.1 \mathrm{M}$ Tris buffer. After 5-10 min incubation, AP positive colonies were displayed in red.

Growth curve. CCK-8 cell counting kit (A311-01, Vazyme, China) was used to calculate growth rate of J1 mES and miPS cells cultured on methanol fixed MEF and NIH3T3 cells along with MMC-MEF feeder cells according to the manufacturer's procedure. $2 \times 10^{3} \mathrm{~J} 1$ or miPS cells were seeded on methanol fixed cells in 48 well plates for $12 \mathrm{~h}$. The MMC-MEF feeders were used as control. Then, $20 \mathrm{uL}$ CCK- 8 regent was added per well and incubated at $37^{\circ} \mathrm{C}$ for $1 \mathrm{~h}$. The absorbance OD values at $450 \mathrm{~nm}$ were then measured as Day 0 .

Immunofluorescence. For immunofluorescence assays, cells were fixed with $4 \%$ paraformaldehyde for 15-30 min at room temperature. The fixed cells were washed twice with PBS, incubated with PBS containing $0.1 \%$ Triton X-100 for $10 \mathrm{~min}$, and washed three times with PBS. After blocking in BSA-blotting buffer (1\% BSA and $0.1 \%$ Tween 20 in PBS) for $30 \mathrm{~min}$, cells were incubated in BSA-blotting buffer with primary antibodies, including anti-Oct4 (1:200, sc-5279, Santa Cruz), anti-Sox2 (1:200, sc-365823, Santa Cruz), anti-Nanog (1:200, ab80892, Abcam), anti-SSEA-1 (1:200, 4744 S, Cell Signaling Technology), anti-Fibronectin (1:100, 15613-1-AP, Proteintech) and anti-Collagen-IV (1:50, 19797-1-AP, Proteintech), in a humidified chamber at $4^{\circ} \mathrm{C}$ overnight. After washing three times, cells were stained for $1 \mathrm{~h}$ with either anti-mouse or anti-rabbit secondary antibody (1:200, Proteintech, China). Nuclei were stained with Hoechst33342 $(10 \mu \mathrm{g} / \mathrm{mL})$ for $2-5 \mathrm{~min}$. Microscopy was performed on a Leica fluorescence microscope.

Flow cytometry analysis. For flow cytometry analysis, pluripotent stem cells were washed once with PBS and then detached with Accutase (Gibco, USA). After centrifugation, cells were washed twice with PBS and resuspended in stain buffer (PBS with $2 \%$ FBS) for cell counting. $1 \times 10^{6}$ cells were then transferred into separate $1.5 \mathrm{ml}$ Eppendorf tubes and incubated in $100 \mu \mathrm{L}$ staining buffer supplemented with FITC-anti-SSEA-1 (\#560886, BD pharmingem, USA) or PE-anti-SSEA-4 antibody ( $\# 330409$, Biolegend, USA) for $30 \mathrm{~min}$ on ice, protected from light. Cells were washed twice and resuspended in $500 \mu \mathrm{L}$ staining buffer and analyzed with FACSCalibur (BD Biosciences). FACS Data were analyzed with FlowJo software.

Scanning Electron Microscope. MEF cells were seeded on round cover slips and cultured to $80 \%$ confluence. After be treated with methanol, $2.5 \%$ glutaraldehyde and MMC, cells were dehydrated stepwise by $10 \%$, $30 \%, 50 \%, 70 \%, 80 \%$, and $90 \%$ ethanol for 10 min. After drying, sticking, metal spraying, samples were observed with Hitachi S4800 Scanning Electron Microscope.

Teratoma formation. Total of 6 samples, including J1-MT-MEF-P30, J1-MT-3T3-P20, J1-MMC-MEF and miPS-MT-MEF-P29, miPS-MT-3T3-P20, miPS-MMC-MEF, were harvested and injected subcutaneously into 
dorsal flanks of immunodeficient mice $\left(5 \times 10^{6}\right.$ cells per injection site). Control mice received $1 x P B S$ only. After 4 weeks, the nude mice were sacrificed and the teratomas were collected, fixed with $4 \%$ paraformaldehyde, and tissues were stained with Hematoxylin and Eosin as the previous description ${ }^{47,48}$. Images were obtained under a Nikon microscope.

Antibiotic-resistant assay. To screening the stable pluripotent stem cell lines, lentiviral vectors pCDH-METTL3-copGFP-Puro and pCDH-miR370-copGFP-Puro were constructed for packing virus. To make lentiviral particles, $2 \times 10^{6} \mathrm{HEK}-293 \mathrm{~T}$ cells were seeded on a $60 \mathrm{~mm}$ cultural dish. When cells reach to $80 \%$ confluence, $4 \mu \mathrm{g}$ each of pCDH-METTL3-copGFP-Puro and pCDH-miR370-copGFP-Puro vectors were transfected into HEK-293T cells together with $4 \mu \mathrm{g}$ pCL-Eco and $2 \mu \mathrm{g}$ pCMV-VSV-G at a ratio of 2:2:1 using Lipofectamine 2000 (Invitrogen). After $48 \mathrm{~h}$ post-transduction, media with viral particles were collected and filtered through $0.45 \mu \mathrm{m}$ filter (Millipore). The collected virus suspension mixed with $8 \mu \mathrm{g} / \mathrm{mL}$ Polybrene were infected into J1 mES and piPS cells. J1 mES cells were cultured in medium with $2 \mu \mathrm{g} / \mathrm{mL}$ puromycin and piPS were cultured in medium with $4 \mu \mathrm{g} / \mathrm{mL}$ puromycin for 1 weeks. The puromycin-resistant colonies of J1 mES and piPS cells were then picked up and expanded in the medium with $2 \mu \mathrm{g} / \mathrm{mL}$ puromycin.

Statistical Analysis. Values were presented as the mean \pm SD. Statistical analyses were performed with SPSS. Two-way ANOVA were used to study differences between grouped data, Student's T tests were performed with one way analysis. Statistical significance was accepted at $P<0.05$. All flow cytometry data were analyzed and generated by FlowJo software.

Data availability. All data generated or analyzed during this study are included in this published article (and its Supplementary Information files).

\section{References}

1. Robinton, D. A. \& Daley, G. Q. The promise of induced pluripotent stem cells in research and therapy. Nature. 481, 295-305, https:// doi.org/10.1038/nature10761 (2012).

2. Saha, K. \& Jaenisch, R. Technical challenges in using human induced pluripotent stem cells to model disease. Cell stem cell. $\mathbf{5}$, 584-595, https://doi.org/10.1016/j.stem.2009.11.009 (2009).

3. Trounson, A. \& McDonald, C. Stem Cell Therapies in Clinical Trials: Progress and Challenges. Cell stem cell. 17, 11-22, https://doi. org/10.1016/j.stem.2015.06.007 (2015).

4. Thomson, J. A. Embryonic Stem Cell Lines Derived from Human Blastocysts. Science. 282, 1145-1147, https://doi.org/10.1126/ science.282.5391.1145 (1998)

5. Takahashi, K. \& Yamanaka, S. Induction of pluripotent stem cells from mouse embryonic and adult fibroblast cultures by defined factors. Cell. 126, 663-676, https://doi.org/10.1016/j.cell.2006.07.024 (2006).

6. Evens, M. \& Kaufman, M. Establishment in culture of pluripotential cells from mouse embryos. Nature. 292, 154-156 (1981).

7. Yang, J. et al. Establishment of mouse expanded potential stem cells. Nature. 550, 393-397, https://doi.org/10.1038/nature24052 (2017).

8. Yang, Y. et al. Derivation of Pluripotent Stem Cells with In Vivo Embryonic and Extraembryonic Potency. Cell. 169, 243-257 e225, https://doi.org/10.1016/j.cell.2017.02.005 (2017).

9. Eiselleova, L. et al. Comparative study of mouse and human feeder cells for human embryonic stem cells. The International journal of developmental biology. 52, 353-363, https://doi.org/10.1387/ijdb.082590le (2008).

10. Llames, S., García-Pérez, E., Meana, Á., Larcher, F. \& del Río, M. Feeder Layer Cell Actions and Applications. Tissue Engineering Part B: Reviews. 21, 345-353, https://doi.org/10.1089/ten.teb.2014.0547 (2015).

11. Talbot, N. C., Sparks, W. O., Powell, A. M., Kahl, S. \& Caperna, T. J. Quantitative and semiquantitative immunoassay of growth factors and cytokines in the conditioned medium of STO and CF-1 mouse feeder cells. In vitro cellular \& developmental biology. Animal. 48, 1-11, https://doi.org/10.1007/s11626-011-9467-7 (2012).

12. Jozefczuk, J., Drews, K. \& Adjaye, J. Preparation of mouse embryonic fibroblast cells suitable for culturing human embryonic and induced pluripotent stem cells. Journal of visualized experiments. 64, e3854, https://doi.org/10.3791/3854 (2012).

13. DA, C. Mouse embryo fibroblast (MEF) feeder cell preparation. Current Protocols in Molecular Biology. 23.2.1-23.2.7, https://doi. org/10.1002/0471142727.mb2302s51 (2000).

14. Draper, J. S. et al. Recurrent gain of chromosomes $17 \mathrm{q}$ and 12 in cultured human embryonic stem cells. Nature biotechnology. 22, 53-54, https://doi.org/10.1038/nbt922 (2004).

15. Xie, C. Q., Lin, G., Luo, K. L., Luo, S. W. \& Lu, G. X. Newly expressed proteins of mouse embryonic fibroblasts irradiated to be inactive. Biochemical and biophysical research communications. 315, 581-588, https://doi.org/10.1016/j.bbrc.2004.01.089 (2004)

16. Martin, M. J., Muotri, A., Gage, F. \& Varki, A. Human embryonic stem cells express an immunogenic nonhuman sialic acid. Nature medicine. 11, 228-232, https://doi.org/10.1038/nm1181 (2005).

17. Villa-Diaz, L. G., Ross, A. M., Lahann, J. \& Krebsbach, P. H. Concise review: The evolution of human pluripotent stem cell culture: from feeder cells to synthetic coatings. Stem cells. 31, 1-7, https://doi.org/10.1002/stem.1260 (2013).

18. Liu, L. et al. Nanofibrous gelatin substrates for long-term expansion of human pluripotent stem cells. Biomaterials. 35, 6259-6267, https://doi.org/10.1016/j.biomaterials.2014.04.024 (2014).

19. Xu, C. et al. Feeder-free growth of undifferentiated human embryonic stem cells. Nature biotechnology. 19, 971-974, https://doi. org/10.1038/nbt1001-971 (2001).

20. Amit, M., Shariki, C., Margulets, V. \& Itskovitz-Eldor, J. Feeder layer- and serum-free culture of human embryonic stem cells. Biology of reproduction. 70, 837-845, https://doi.org/10.1095/biolreprod.103.021147 (2004).

21. Rodin, S. et al. Long-term self-renewal of human pluripotent stem cells on human recombinant laminin-511. Nature biotechnology. 28, 611-615, https://doi.org/10.1038/nbt.1620 (2010).

22. Braam, S. R. et al. Recombinant vitronectin is a functionally defined substrate that supports human embryonic stem cell self-renewal via alphavbeta5 integrin. Stem cells. 26, 2257-2265, https://doi.org/10.1634/stemcells.2008-0291 (2008).

23. Brafman, D. A. et al. Long-term human pluripotent stem cell self-renewal on synthetic polymer surfaces. Biomaterials. 31, 9135-9144, https://doi.org/10.1016/j.biomaterials.2010.08.007 (2010).

24. Zhou, P. et al. Simple and versatile synthetic polydopamine-based surface supports reprogramming of human somatic cells and long-term self-renewal of human pluripotent stem cells under defined conditions. Biomaterials. 87, 1-17, https://doi.org/10.1016/j. biomaterials.2016.02.012 (2016).

25. Higuchi, A. et al. Long-term xeno-free culture of human pluripotent stem cells on hydrogels with optimal elasticity. Scientific reports. 5, 18136, https://doi.org/10.1038/srep18136 (2015). 
26. Yang, J. J., Liu, J. F., Kurokawa, T., Kitada, K. \& Gong, J. P. Hydrogels as feeder-free scaffolds for long-term self-renewal of mouse induced pluripotent stem cells. Journal of tissue engineering and regenerative medicine. 9, 375-388, https://doi.org/10.1002/ term.1640 (2015).

27. Higuchi, A., Ling, Q. D., Ko, Y. A., Chang, Y. \& Umezawa, A. Biomaterials for the feeder-free culture of human embryonic stem cells and induced pluripotent stem cells. Chemical reviews. 111, 3021-3035, https://doi.org/10.1021/cr1003612 (2011).

28. Higuchi, A. et al. Design of polymeric materials for culturing human pluripotent stem cells: Progress toward feeder-free and xenofree culturing. Progress in Polymer Science. 39, 1348-1374, https://doi.org/10.1016/j.progpolymsci.2014.01.002 (2014).

29. Lu, H. F. et al. A 3D microfibrous scaffold for long-term human pluripotent stem cell self-renewal under chemically defined conditions. Biomaterials. 33, 2419-2430, https://doi.org/10.1016/j.biomaterials.2011.11.077 (2012).

30. Wei, J. et al. The importance of three-dimensional scaffold structure on stemness maintenance of mouse embryonic stem cells. Biomaterials. 35, 7724-7733, https://doi.org/10.1016/j.biomaterials.2014.05.060 (2014).

31. Joddar, B., Nishioka, C., Takahashi, E. \& Ito, Y. Chemically fixed autologous feeder cell-derived niche for human induced pluripotent stem cell culture. Journal of Materials Chemistry B. 3, 2301-2307, https://doi.org/10.1039/c4tb01635a (2015).

32. Yue, X. S. et al. Feeder cells support the culture of induced pluripotent stem cells even after chemical fixation. PloS one. 7, e32707, https://doi.org/10.1371/journal.pone.0032707 (2012).

33. Ito, Y., Kawamorita, M., Yamabe, T., Kiyono, T. \& Miyamoto, K. Chemically fixed nurse cells for culturing murine or primate embryonic stem cells. Journal of bioscience and bioengineering. 103, 113-121, https://doi.org/10.1263/jbb.103.113 (2007).

34. Kim, S. H., Turnbull, J. \& Guimond, S. Extracellular matrix and cell signalling: the dynamic cooperation of integrin, proteoglycan and growth factor receptor. The Journal of endocrinology. 209, 139-151, https://doi.org/10.1530/JOE-10-0377 (2011).

35. Brizzi, M. F., Tarone, G. \& Defilippi, P. Extracellular matrix, integrins, and growth factors as tailors of the stem cell niche. Current opinion in cell biology. 24, 645-651, https://doi.org/10.1016/j.ceb.2012.07.001 (2012).

36. Boettiger, D. Mechanical control of integrin-mediated adhesion and signaling. Current opinion in cell biology. 24, 592-599, https:// doi.org/10.1016/j.ceb.2012.07.002 (2012).

37. Mazzieri, R. et al. Control of type IV collagenase activity by components of the urokinase-plasmin system: a regulatory mechanism with cell-bound reactants. The EMBO journal. 16, 2319-2332, https://doi.org/10.1093/emboj/16.9.2319 (1997).

38. Yu, J. et al. Induced Pluripotent Stem Cell Lines Derived from Human Somatic Cells. Science. 318, 1917-1920, https://doi. org/10.1126/science.1151526 (2007).

39. Takahashi, K. et al. Induction of pluripotent stem cells from adult human fibroblasts by defined factors. Cell. 131, 861-872, https:// doi.org/10.1016/j.cell.2007.11.019 (2007).

40. Zhou, Y. et al. The significance of membrane fluidity of feeder cell-derived substrates for maintenance of iPS cell stemness. Scientific reports. 5, 11386, https://doi.org/10.1038/srep11386 (2015).

41. Jaggy, M. et al. Hierarchical Micro-Nano Surface Topography Promotes Long-Term Maintenance of Undifferentiated Mouse Embryonic Stem Cells. Nano letters. 15, 7146-7154, https://doi.org/10.1021/acs.nanolett.5b03359 (2015).

42. Liu, L. et al. Chemically-defined scaffolds created with electrospun synthetic nanofibers to maintain mouse embryonic stem cell culture under feeder-free conditions. Biotechnology letters. 34, 1951-1957, https://doi.org/10.1007/s10529-012-0973-9 (2012).

43. Lyu, Z. et al. Maintaining the pluripotency of mouse embryonic stem cells on gold nanoparticle layers with nanoscale but not microscale surface roughness. Nanoscale. 6, 6959-6969, https://doi.org/10.1039/c4nr01540a (2014).

44. Gershlak, J. R. \& Black III, L. D. Beta 1 integrin binding plays a role in the constant traction force generation in response to varying stiffness for cells grown on mature cardiac extracellular matrix. Experimental cell research. 330, 311-324, https://doi.org/10.1016/j. yexcr.2014.09.007 (2015).

45. Narva, E. et al. A Strong Contractile Actin Fence and Large Adhesions Direct Human Pluripotent Colony Morphology and Adhesion. Stem cell reports. 9, 67-76, https://doi.org/10.1016/j.stemcr.2017.05.021 (2017).

46. Lee, J., Abdeen, A. A., Tang, X., Saif, T. A. \& Kilian, K. A. Geometric guidance of integrin mediated traction stress during stem cell differentiation. Biomaterials. 69, 174-183, https://doi.org/10.1016/j.biomaterials.2015.08.005 (2015)

47. Zhang, S. et al. Generation of intermediate porcine iPS cells under culture condition favorable for mesenchymal-to-epithelial transition. Stem cell reviews and reports. 11, 24-38, https://doi.org/10.1007/s12015-014-9552-x (2015).

48. Cheng, D. et al. Porcine induced pluripotent stem cells require LIF and maintain their developmental potential in early stage of embryos. PloS one. 7, e51778, https://doi.org/10.1371/journal.pone.0051778 (2012).

\section{Acknowledgements}

This work was supported by the National Natural Science Foundation of China (No. 31571521 and 31371505).

\section{Author Contributions}

Conceived and designed the experiments: H.W. Performed the experiments: Y.R., Z.M., T.Y., M.L. Analyzed the data: Y.R., H.W. Contributed reagents/materials/analysis tools: Y.R., Z.M. Wrote the paper: Y.R., H.W. All authors have given approval to the final version of the manuscript.

\section{Additional Information}

Supplementary information accompanies this paper at https://doi.org/10.1038/s41598-018-26238-2.

Competing Interests: The authors declare no competing interests.

Publisher's note: Springer Nature remains neutral with regard to jurisdictional claims in published maps and institutional affiliations.

Open Access This article is licensed under a Creative Commons Attribution 4.0 International

License, which permits use, sharing, adaptation, distribution and reproduction in any medium or format, as long as you give appropriate credit to the original author(s) and the source, provide a link to the Creative Commons license, and indicate if changes were made. The images or other third party material in this article are included in the article's Creative Commons license, unless indicated otherwise in a credit line to the material. If material is not included in the article's Creative Commons license and your intended use is not permitted by statutory regulation or exceeds the permitted use, you will need to obtain permission directly from the copyright holder. To view a copy of this license, visit http://creativecommons.org/licenses/by/4.0/.

(C) The Author(s) 2018 